\title{
Photoprotection in adolescents: what they know and how they behave*
}

\author{
Gabriel Martinez Andreola ${ }^{1}$ \\ Janaina Huczok ${ }^{3}$ \\ Kerstin Taniguchi Abagge ${ }^{2}$
}

\author{
Vânia Oliveira de Carvalho² \\ Mônica Nunes Lima Cat ${ }^{2,4}$
}

DOI: http:/ / dx.doi.org/10.1590/abd1806-4841.20185489

\begin{abstract}
BACKGROUND: The greatest sun exposure occurs until adolescence and this is the only factor involved in photocarcinogenesis subject to modification with photoprotection.

Овјестіvе: The objective of this study was to evaluate the habits and knowledge of adolescents regarding photoprotection.

MethoD: Cross-sectional study that included 512 students from primary and high school. Data were collected by questionnaires with questions about habits and knowledge on sun protection. For data analysis, Pearson's Chi-square test and Yates test were applied, with $5 \%$ level of significance.

RESULTS: We evaluated 512 students, with a mean age of 14 years old. The teenagers agreed that ultraviolet rays cause skin cancer and aging (96\% and 70\%, respectively). Knowledge about the occurrence of burns even on cloudy days was recorded in $68 \%$ of cases, as well as the need for photoprotection for sports in $72 \%$. The source of information about sun protection were by parents in $55 \%$. In $70 \%$ was observed previous occurrence of sunburn, the daily use of sunscreens was found in $15 \%$ and $67 \%$ used only at the beach. of sunscreens with SPF higher than 30 was reported by $70 \%$ of students and $57 \%$ reported going to the beach between $10 \mathrm{~h}$ and $16 \mathrm{~h}$. In $68 \%$ of cases it was registered insufficient sun protection, attributed, in $57 \%$ of the time to forgetfulness.
\end{abstract}

STUDY LIMITATIONS: The sample refers to two schools of Curitiba (PR), Brazil.

CONCLUSION: Teenagers know the risks of sun exposure, but they do not adopt the practices for adequate protection.

Keywords: Adolescent; Health knowledge, attitudes and practice; Sun protection factor; Skin neoplasms; Sunscreening agents

\section{INTRODUCTION}

Ultraviolet (UV) radiation from the sun is fundamental for the metabolism of vitamin D, which is essential to bone health and has been associated with many other roles. However, UV type A and $\mathrm{B}$ are associated to skin cancer development. ${ }^{1,2}$

Exposure to sunlight during childhood and adolescence occurs more intensely than in the majority of adults because of outdoors recreational activities and sports. This social behavior is associated to a higher risk of development of skin cancer in adult life. ${ }^{3}$ Moreover, the risk of photoaging of the skin and the appearance of sunspots on skin is higher if there is excessive sun exposure during childhood. ${ }^{4}$ Innumerous campaigns have been promoted to spread the knowledge on this subject and to stimulate adherence to healthy photoprotection practices. However, is it possible that teenagers are affected by these campaigns?
In a cross-sectional study using questionnaires for 887 Swiss students, it was observed that the knowledge on photoprotection and sun damage are adequate, however, the practices are not. A small number of teenagers opts for shade in sunny days, the majority uses sunscreens sporadically and had at least one sunburn. ${ }^{5}$

A study performed in the southern region of Brazil (Carlos Barbosa, RS), in 2010, included 775 high school students and registered that only $15.4 \%$ used sunscreens daily; $73 \%$ had already had sunburns. ${ }^{6}$

Batista et al. (2013) $)^{7}$ applied questionnaires in 361 parents of preschool students in Santa Catarina in order to investigate their practices of skin care for their children and detected that sunscreens were used insufficiently and incorrectly.

\footnotetext{
Received on 10.12.2015.

Approved by the Advisory Board and accepted for publication on 15.08.2016.

* Study conducted at the Department of Pediatrics, Hospital de Clínicas, Universidade Federal do Paraná (UFPR) - Curitiba (PR), Brazil. Financial support: None.

Conflict of interest: None.

Department of Dermatology, Hospital de Clínicas, Universidade Federal do Paraná (UFPR) - Curitiba (PR), Brazil.

Department of Pediatrics, Hospital de Clínicas, Universidade Federal do Paraná (UFPR) - Curitiba (PR), Brazil.

Pediatrics Outpatient Clinic, Hospital Regional de Cacoal (HRC) - Cacoal (RO), Brazil.

Post-Graduation Program in Child and Adolescent Health, Hospital de Clínicas, Universidade Federal do Paraná (UFPR) - Curitiba (PR), Brazil.
} 
Due to the importance of photoprotection and because of the few studies about knowledge and practices, especially in Brazil, the objective of this study is to determine the knowledge and practices on photoprotection of teenagers.

\section{METHODS}

Cross-sectional, analytic study, with prospective data collection. The cases were teenage students of schools in Curitiba. The study was approved by the ethics in research committee of the Hospital de Clínicas, Universidade Federal do Paraná and the schools; the students and their parents signed an authorization form for the participation in the study and a consent form, respectively.

Students from one public and one private school were included, with ages ranging from 13 to 18 years, in year 8 or 10 of school and those who did not fill out the form correctly, even after explanation from the researchers, were excluded

A standard questionnaire was applied in order to establish the practices and the level of knowledge of the students on photoprotection between May and November 2013. There were 28 questions subdivided into seven sections with essay, dichotomous, bipolar questions, with an option of lack of knowledge expressed as yes, no, and I don't know, and a reduced Likert scale (always/ sometimes/never).

General population data were assessed, such as: age, sex, phototype, type of school, parent schooling, and parent occupation. The phototype was self-chosen, according to the description of Fitzpatrick's classification in the questionnaire, associated to pictures as an example for each phototype.

Knowledge in regards to radiation and sun protection were part of the second section of the questionnaire and the level of knowledge of the students about the dangers of UV radiation and its relationship with skin carcinogenesis, phototypes that are more and less prone to sunburn, meaning and recommendation of SPF and where this knowledge was acquired were evaluated. Based on the 10 questions, a score was created to evaluate the level of knowledge of the students and grades were applied for each correct answer, ranging from 0 to 10 .

In the third section of the questionnaire, it was also evaluated whether the adolescents feel happier when their skin is tanned and also their behavior on the subject. The questionnaire also approached the frequency of, symptoms, and activities performed prior to sunburns, and how each individual protects themselves to avoid sunburns, which was the fourth section.

Photoprotection practices were part of the fifth section and were evaluated with questions such as: sunscreen use practices, the frequency and application methods, how they behaved in regards to sun exposure, and what time they exposed, the reasons for exposure and if they used clothes in a daily basis for protection.

The role of the parents or guardians was evaluated in regards to the passing of information, warnings and encouragement on photoprotection and the level of difficulty in answering the questionnaire, which corresponded to the sixth and seventh section, respectively.

The questionnaires were applied during the interval between two classes of the curriculum, with approval of the teacher responsible for the class upon arrival of the researchers.
The sample size was estimated by the sample estimation for proportions with an effect magnitude of 0.40 and the level of significance of $5 \%$, conferring a test power of $95 \%$. For data analysis, Pearson chi-square test and Yates test were used.

\section{RESULTS}

In total, 535 questionnaires were applied and 23 were excluded due to being incomplete or incorrect, with a final sample of 512 students. The characteristics of the population are presented in table 1.

\section{Knowledge about photoprotection}

Of the students, $96.0 \%$ (492) answered they knew the relationship between the degree of sun exposure and skin cancer; $94.1 \%$ (482) that the sun causes sunspots on the skin; 83.2\% (426) that prolonged exposure causes wrinkles; and 69.5\% (356) that photoaging is directly related to a more intense sun exposure.

In the question about which skin phototypes will confer higher natural protection against sun exposure, $42.1 \%$ (216) selected the correct phototype and 70.5\% (361) got right the correct SPF for each phototype.

The knowledge that a higher SPF will allow more time of sun exposure was recognized as true in $80.2 \%$ (411) of the answers. The direct relationship between the sunscreen factor and the time allowed in the sun was recognized as false in $80.8 \%$ (414) of the answers.

A total of $350(68.4 \%)$ students answered that the risks of sun exposure are present even in cloudy days. The percentage of answers about knowledge on photoprotection is described in table 2.

Being tanned was considered a desired beauty standard in $61.8 \%$ (317) of the cases, being more frequent among females $(70.5 \%$ versus $50.8 \%$; $\mathrm{p}<0.001)$, as shown in graph 1 .

The score of knowledge was assessed in 431 students because incomplete questionnaires were excluded. Of the girls that answered to the 10 questions on knowledge, 163 (69.1\%) got eight or more right, and 107 of the boys $(54.9 \%), p=0.008$. For scores below seven questions there was no statistically significant difference (Graph 2).

The source of knowledge on photoprotection were the parents in 55\% (282) of the cases, the school in $21 \%$ (109), the campaigns in $12.5 \%$ (64) and other sources in $8.0 \%$ (41). Do not know or did not answer $1.8 \%$ (9), and more than one source of information was answered by $1.4 \%(7)$ of the students.

TABLE 1: Characteristics of the study population

\begin{tabular}{|cc|}
\hline Gender & Absolute number (\%) \\
\hline Male & $228(44.5)$ \\
\hline Female & $282(55.0)$ \\
\hline NA & $2(0.50)$ \\
\hline Phototypes & Absolute number (\%) \\
\hline I or II & $128(25.0)$ \\
\hline III or IV & $326(63.8)$ \\
\hline V or VI & $57(11.2)$ \\
\hline NK or NA & $1(0.2)$ \\
\hline
\end{tabular}

$\mathrm{NK}=$ Does not know. NA $=$ Did not answer 


\section{Practices on photoprotection}

In regards to photoprotection practices, $68.1 \%$ (349) said they do not adequately protect against the sun. When asked about "what reasons prevent you from protecting better", $57.0 \%$ (215) said they forget, $16.1 \%$ (61) said they don't like and 26.9\% (236) do not know or did not answer.

In regards to the time of sun exposure, $56.8 \%$ (291) exposed at an inappropriate time, between $10 \mathrm{AM}$ and 4 PM. When asked if they use a sunscreen with a lower SPF to allow tanning, 75.2\% (385) denied this practice, but $22.8 \%$ (117) said it was a common practice; $2 \%$ (10) did not answer.

\section{Sunburns}

In the last year, $69.1 \%$ (354) of the students had a sunburn, with $50.8 \%$ (180) with one sunburn, $22.3 \%$ (79) with two and $26.8 \%$ (95) with three or more. Sunburn occurred during leisure activities in the pool or at the beach in $90.1 \%$ (319) of times, followed by those related to outdoor sports ( $12.4 \%$ or 44 cases) and in $13.8 \%$ (49) there were other reasons.

TABLE 2: Percentage of answers for the items related to photoprotection knowledge

\begin{tabular}{lc}
\hline “Can UV rays cause skin cancer?” & Absolute number (\%) \\
\hline Yes & $492(96.0)$ \\
\hline No & $16(3.2)$ \\
\hline NK or NA & $4(0.8)$ \\
\hline “Can UV rays cause early aging?” & Absolute number (\%) \\
Yes & $356(69.5)$ \\
No & $152(29.7)$ \\
NK or NA & $4(0.8)$
\end{tabular}

"Which of the three depicted persons should have a higher natural protection against Absolute number (\%) sunburn?" (Phototypes I, III or V)

$\begin{array}{lc}\text { Right } & 216(42.1) \\ \text { Wrong } & 280(54.7) \\ \text { NK or NA } & 16(3.2)\end{array}$

"The higher the SPF, the more protected you will be against sunburns?"

Absolute number (\%)

\begin{tabular}{lc} 
True & $411(80.2)$ \\
False & $56(11.0)$ \\
\hline NK or NA & $45(8.8)$
\end{tabular}

"Can sunburns occur even on cloudy days?"

Absolute number (\%)

$\begin{array}{lc}\text { Yes } & 350(68.4) \\ \text { No } & 158(30.8) \\ \text { NK or NA } & 4(0.8)\end{array}$

$\mathrm{NK}=$ Does not know. $\mathrm{NA}=$ Did not answer.

\section{Sunscreen use}

Sunscreen use as the main method to protect from the sun was selected in $56.3 \%$ (288) of the questionnaires, followed by being in the shade in $10 \%$ (51); $10.5 \%$ (54) of the students said they do not protect, 3.3\% (17) do not recall, 1\% (5) use other methods and 19\% (97) did not answer.

During summer sunny days, $51 \%$ (263) of the students said they use sunscreens sometimes, $24.2 \%$ (124) never, $23.2 \%$ (119) almost always and $1.2 \%$ (6) did not answer.

For outdoors sports, $44.7 \%$ (229) said they never use sunscreen (table 3).

In relation to SPF, $281(57.0 \%)$ answered they use 30 . SPF 15 came second with 112 (21.9\%) students, followed by SPF 50 or above with 84 (16.4\%). Lastly, 6 (1.1\%) students said they use SPF 8 and 19 (3.6\%) did not answer.

Table 3 summarizes some of the answers in regards to photoprotection practices, sunscreen use and sunburns.

The greater sunscreen use was at the beach in $66.7 \%$ (342) of cases, followed by "sunny days" in $15.4 \%$ (79) and in $2 \%(10)$

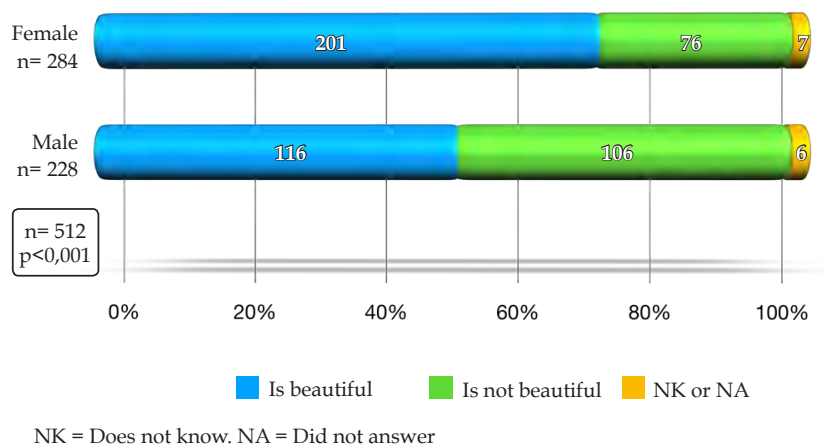

GRAPH 1: Analysis of the preference of tanned skin according to gender

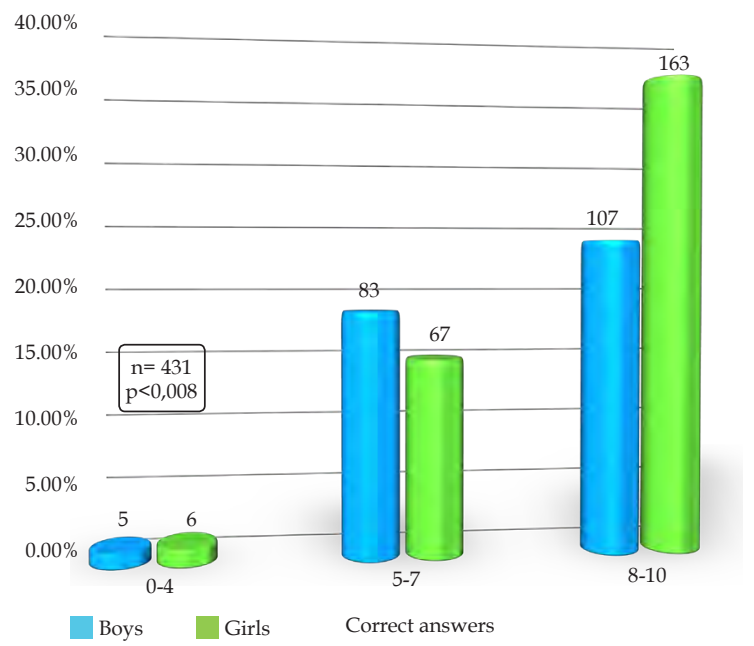

GraPH 2: Distribution of the score on the knowledge about photoprotection according to gender 
TABLE 3: Percentage of answers to the questions about photoprotection practices

\begin{tabular}{|lc|}
\hline “Adequate protection?" & Absolute number (\%) \\
\hline Yes & $150(28.2)$ \\
\hline No & $349(68.1)$ \\
\hline NK or NA & $13(2.7)$ \\
\hline “In which hours do you \\
normally expose to the \\
sun?" (Adequate: before \\
10 AM and after 3 PM) & Absolute number (\%) \\
\hline Adequate & \\
\hline Inadequate & $49(9.5)$ \\
\hline NK or NA & $291(56.8)$ \\
\hline “Did you have any & $172(33.6)$ \\
\hline sunburn last year?" & Absolute number (\%) \\
\hline Yes & $354(69.1)$ \\
\hline No & $122(23.8)$ \\
\hline NK or NA & $36(7.1)$ \\
\hline “Do you use sunscreen \\
\hline $\begin{array}{l}\text { during outdoor } \\
\text { activities?" }\end{array}$
\end{tabular}

"always", regardless of being at the beach or being a sunny day. Eighty-one teenagers (15.6\%) could not or did not answer.

During summer, $52.0 \%$ (266) of the students said they preferred to remain in the sun, while $46.3 \%$ (237) in the shade and $1.7 \%$ (9) did not answer. Females answered they prefer the sun $(61.6 \%$ or 175) more than males $-39.9 \%(91)$, as described in graph $3(p<0.001)$.

\section{DISCUSSION}

Despite the level of knowledge assessed being good and similar to what was observed by Reinau et al. ${ }^{5}$ in regards to the relationship of sun exposure and increased skin cancer risk and photoaging, less than half of the students evaluated by the Swiss authors knew about the relationship between sun exposure and skin aging, whereas in the sample studied here, $69.5 \%$ appeared to have that knowledge.

The most frequent phototypes among the students were III and IV, in $63.7 \%$, according to the typical prevalence in the south

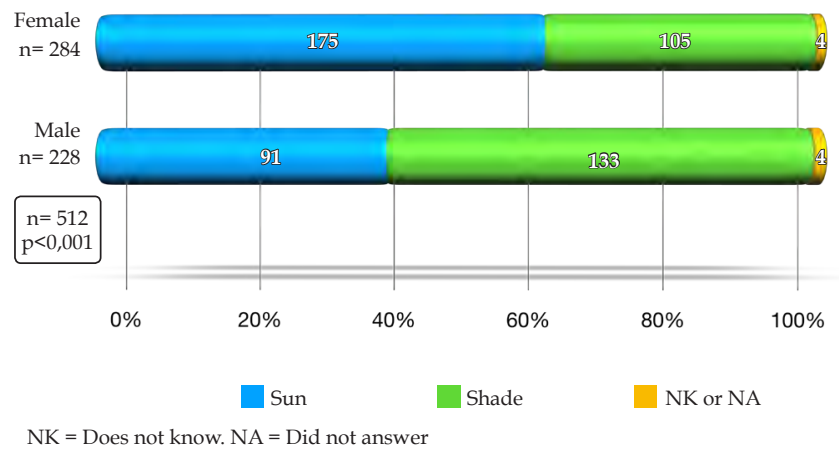

GraPH 3: Analysis of the preference to stay in the sun or in the shade by gender

of Brazil, where there is predominance of lighter phototypes, with increased risk when exposed to the sun. ${ }^{8}$

According to an application developed in 2013 by the National Tourism Agency of Brazil (Embratur), Curitiba was the capital city with less sunny days in all Brazilian capital cities, including cities renowned by a cloudy climate, such as New York, London, Berlin, and Prague. ${ }^{9}$ The question regarding the use of sunscreen even in cloudy days demonstrated that this is not a practice adopted by teenagers, since $30.8 \%$ did not think it was necessary to use sunscreen in cloudy days, typical of the capital of Paraná. This is worrisome since UV radiation is present even in cloudy days and even in rainy days..$^{10}$ Future campaigns should focus on the need of daily use of sunscreens including the winter months. ${ }^{11}$

In regards to the knowledge of the relationship between the phototype and the natural protection to sun exposure, a Swiss study observed that $95 \%$ of the students answered correctly. Among the teenagers evaluated in this study, more than half (54.7\%) answered incorrectly by not selecting dark skinned woman (phototype VI) as having a higher natural protection against sun exposure. The knowledge of the phototype leads to a correct choice of the most appropriate SPF for each skin type. Besides, the risks of sun exposure are higher the lower the phototype, because a fair skinned person, despite having the same amount of melanocytes as a dark skinned person, will produce less melanin and, therefore, will have a less effective protection against UV rays. ${ }^{12}$

The SPF is a grading system developed to quantify the degree of protection provided by a topical sunscreen against cutaneous erythema caused by UVB radiation. Thus, the higher the SPF, the longer the time for the development of erythema. ${ }^{3}$ In the present study, SPF 30 was more frequently chosen by the students. Batista et al. ${ }^{7}$ described that $95.2 \%$ of preschoolers parents used SPF above 15. This seems to indicate that people know that a SPF 15 or lower sunscreen is less effective.

The students demonstrated to have a good level of knowledge regarding the meaning of the abbreviation SPF. In the study by Reinau et al. ${ }^{5}, 80 \%$ of the adolescents knew that the higher the SPF of the sunscreen, the longer the time one person can expose to the sun without turning red. ${ }^{13}$ In the present study, the knowledge of this information was similar. 
Despite the evaluation of the score demonstrate that knowledge on photoprotection and exposure risks are adequate among the students presently assessed, especially among females, more than half of the study population considered tan beautiful, with a higher percentage among females. This supports the need for the elaboration of campaigns that reinforce the notion that there is no such thing as safe tanning. Reinau et al. ${ }^{5}$ observed that $49 \%$ of their sample of students did not care about tanning, a finding that can be explained by climate and cultural differences of the populations evaluated. Both in this study and the Swiss study, the majority of teenagers affirmed having received information about photoprotection and sun exposure risks from their parents. ${ }^{5}$ On the other hand, one study performed in two American universities showed that more than half of the sample acquired the knowledge through magazines and newspapers. ${ }^{14}$

In regards to the practices of teenagers, around $70 \%$ of all the students said they do not adequately protect against sun rays and more than half attributed this to forgetfulness. American teenagers were also inquired about the sufficiency of photoprotection and $58 \%$ answered they do not protect adequately. ${ }^{14}$ Moreover, more than half expose to the sun in contraindicated times of the day, according to global consensus, including the Brazilian Consensus on Photoprotection that considers inadequate the exposure between $10 \mathrm{AM}$ and $3 \mathrm{PM} \cdot{ }^{15}$ In a cross-sectional study in the city of Carlos Barbosa (RS), that assessed sun exposure and protection practices in 775 high-school students, Dupont and Pereira ${ }^{6}$ found that $60 \%$ of the students were exposing in inadequate times.

The occurrence of sunburn during childhood and adolescence, the number of sunburns throughout life and recent sunburns are associated to an increased risk in developing melanoma. ${ }^{16} \mathrm{Ap}-$ proximately $70 \%$ of the students said they had some type of sunburn in the last year; in the study by Reinau et al. ${ }^{5}$, the same information was given by $56 \%$ of the students. Despite the knowledge being similar between the students evaluated in this study and the Swiss, the inappropriate practices, associated to the fact that Brazil is a tropical country with a higher incidence of UV radiation, can have determined the higher number of sunburns among the students assessed in the present study.

Ninety percent of sunburns occurred while swimming in the ocean, during swimming classes or water sports, followed by
$12.4 \%$ by outdoor sports. It is known that regular physical exercises are indicated to obtain a healthy life style, however, guidance must be offered by health care professionals about risks related to daily activities and outdoor sports and the need for adequate photoprotection. ${ }^{17}$

With the popularization of sunscreens in the 1970s, they became the main agents used during sun exposure in order to prevent the damage caused by UV rays. ${ }^{13,18}$ In the present study, $56 \%$ said they use sunscreens as the main method of sun protection, especially at the beach and on sunny days. In regards to the frequency of use, only $12 \%$ of the students used daily sunscreens, which is the recommendation by the Brazilian Photoprotection Consensus, and $44 \%$ said they never use sunscreens during the practice of outdoor sports. Among Swiss students, a frequent use was observed in $36 \%$ of cases, and "rarely" in 18\%, what was associated to a poor knowledge on the subject. ${ }^{5,15}$

Besides sunscreen use and avoidance of sun exposure in inadequate hours, other types of sunburn prevention include using adequate clothing and staying in the shade. ${ }^{19}$ During summer, only $46.3 \%$ of the students from Curitiba prefer shades instead of sun, and this preference is statistically significant when females are compared to males, what could be explained by the concern with current beauty standards. In Switzerland, Reinau et al. ${ }^{5}$ observed that $32 \%$ of the students remained in the shade on sunny days. That is, the teenagers know the risks, but they continue exposing to the sun.

The role of parents in the guidance and active interference in photoprotection practices was seen in $42.8 \%$ of the students in this study and in $52.5 \%$ of Swiss students. Reinau et al. ${ }^{5}$ also noted that this role was less frequent in families with a lower education level.

\section{CONCLUSION}

Teenagers know of the risks of sun exposure, but have inappropriate photoprotection practices. The schools and the parents were the main source of information and the main factors that interfered in the level of knowledge on photoprotection. It is essential to promote a reorganization in the campaigns for photoprotection, using more specific contents to each age group, as well as emphasizing the daily measures of protection in the cities, both in summer and winter. $\square$ 


\section{REFERENCES}

1. Osterlind A, Tucker MA, Stone BJ, Jensen OM. The Danish case-control study of cutaneous malignant melanoma. II. Importance of UV-light exposure. Int J Cancer. 1988;42:319-24.

2. Narayanan DL, Saladi RN, Fox JL. Ultraviolet radiation and skin cancer. Int $\mathrm{J}$ Dermatol. 2010:49:978-86.

3. Criado PR, Melo JN, Oliveira ZN. Fotoproteção tópica na infância e na adolescência. J Pediatr (Rio J.) 2012;88:203-10.

4. Ghazi S, Couteau C, Paparis E, Coiffard LJ. Interest of external photoprotection by means of clothing and sunscreen products in young children. J Eur Acad Dermatol Venereol. 2012;26:1026-30.

5. Reinau D, Meier C, Gerber N, Hofbauer GF, Surber C. Sun protection behavior of primary and secondary school students in North-Western Switzerland. Swiss Med Wkly. 2012;142:w13520.

6. Dupont L, Pereira DN. Sun exposure and sun protection habits in high school students from a city south of the country. An bras Dermatol. 2012;87:90-5

7. Batista T, Fissmer MC, Porton KR, Schuelter-Trevisol F. Assessment of sun protection and skin cancer prevention among preschool children. Rev Paul Pediatr. 2013;31:17-23

8. Ipardes.pr.gov.br [Internet]. Características Demográficas e Sociais da População, 1980 - 2010 [acesso 01 Maio 2014]. Disponível em: http://www.ipardes.pr.gov. br/anuario 2010/estrutura.html.

9. Gazetadopovo.com.br [Internet]. Curitiba tem menos dias de sol do que NY, Londres, Berlin e Praga [acesso 01 Maio 2014]. Disponível em: www. gazetadopovo.com.br/vidaecidadania/conteudo.phtml?id=1437743.

10. Talhari S, Lupi 0. Fotoproteção e fotoprotetores. In: Neves RG, Lupi 0, Talhari S Câncer da pele. Rio de Janeiro: MEDSI; 2001. p.672-9.

11. Dadlani C, Orlow SJ. Planning for a brighter future: a review of sun protection and barriers to behavioral change in children and adolescents. Dermatol Online J. 2008;14:1.

12. Gloster HM Jr, Neal K. Skin cancer in skin of color. J Am Acad Dermatol. 2006:55:741-60.

13. Shalka S, Reis VMS. Fator de proteção solar: significado e controvérsias. An Bras Dermatol. 2011;86:507-15
14. Grunfeld EA. What Influences University Students' Intentions to Practice Safe Sun Exposure Behaviors? J Adolesc Health. 2004:35:486-92.

15. Schalka S, Steiner D, Ravelli FN, Steiner T, Terena AC, Marçon CR, et al. Consenso Brasileiro de Fotoproteção. An Bras Dermatol. 2014;89:S6-75.

16. Juchem PP, Hochberg J, Winogron A, Ardenghy M, English R. Riscos à saúde da radiação ultravioleta. Rev Bras Cir Plást.1998;13:31-60

17. Purim KSM, Leite N. Fotoproteção e exercício físico. Rev Bras Med Esporte. 2010;16:20-8.

18. Godar DE, Urbach F, Gasparro FP, van der Leun JC. UV doses of young adults. Photochem Photobiol. 2003;77:453-7.

19. Gies P. Photoprotection by clothing. Photodermatol Photoimmunol Photomed. 2007;23:264-74.

How to cite this article: Andreola GM, Carvalho VO, Huczok J, Cat MNL, Abagge KT. Photoprotection in adolescents: what they know and how they behave. An Bras Dermatol. 2018;93(1): 39-44. 